\title{
Erythrocyte Incorporation of Ingested 58-Iron by Infants
}

\author{
SAMUEL J. FOMON, MORTEZA JANGHORBANI, BILL T. G. TING, EKHARD E. ZIEGLER, \\ RONALD R. ROGERS, STEVEN E. NELSON, LYNDA S. OSTEDGAARD, AND \\ BARBARA B. EDWARDS \\ Department of Pediatrics, College of Medicine, University of Iowa, Iowa City, Iowa 52242, and Department of \\ Pathology, School of Medicine, Boston University, Boston, Massachusetts 02118
}

\begin{abstract}
The least abundant stable isotope of iron, ${ }^{58} \mathrm{Fe}$ (natural abundance 0.322 weight $\%$ ), was administered orally to infants to explore the feasibility of using a stable rather than a radioisotope in studies of iron absorption. The dose of ${ }^{58} \mathrm{Fe}$ was given between feedings at age 126 days. The mass isotope ratio, ${ }^{58} \mathrm{Fe} /{ }^{57} \mathrm{Fe}$, was determined in blood by inductively coupled plasma mass spectroscopy and at ages 140, 168, and 196 days. The percentage of the ${ }^{58} \mathrm{Fe}$ dose entering the circulation $(3.2$ to $16.0 \%)$ was inversely correlated with serum ferritin concentration $(r=$ $-0.867, p<0.01$ ). For individual infants the SD of the percentage of administered dose of iron appearing in the circulation ranged from 0.22 to 1.28 . We conclude that the method is likely to be suitable for within-subject comparisons of iron availability from foods. Because of the large between-subject variation, we are pessimistic for this age group about the usefulness of study designs based on group comparisons. (Pediatr Res 24: 20-24, 1988)
\end{abstract}

\section{Abbreviations}

ICP/MS, inductively coupled plasma mass spectrometry MIR, mass isotope ratio

MR, measured ratio

Iron deficiency is a leading nutritional deficiency disorder among infants and children both in industrialized and developing countries (1). Although it is well recognized that development of strategies for prevention of iron deficiency requires sound knowledge of iron absorption, studies to provide this knowledge have been impeded by reluctance to administer radioisotopes to young subjects. We have recently demonstrated the feasibility of using the least abundant stable isotope of iron, ${ }^{58} \mathrm{Fe}$ (natural abundance 0.322 weight \%), for studies of iron metabolism in infants and have reported data from study of four infants (2). We reported the MIR 58/57 in erythrocytes for each of four infants at 84 and 112 days of age (baseline values) and at 140, 168, and 196 days of age. A dose of ${ }^{58} \mathrm{Fe}$ was administered to each infant under standardized conditions at 126 days of age. We concluded that ${ }^{58} \mathrm{Fe}$ was promising as a tracer for studies of iron availability in infants.

We have now studied an additional five infants and, from the pooled data, have made estimates of the apparent errors of the method. We have also demonstrated for the first time in infants

Received November 20, 1987; accepted February 25, 1988.

Correspondence Samuel J. Fomon, M.D., Department of Pediatrics, University of Iowa Hospital, lowa City, IA 52242.

Supported in part by USPHS Grants HD 07578 and AM 34964 and grants from the Bristol-Myers Company and H.J. Heinz Company. a negative correlation between serum ferritin concentration and erythrocyte incorporation of iron.

\section{METHODS}

Subjects. The subjects were normal Caucasian term infants recruited from those enrolled in studies of food intake and growth in the Division of Nutrition, Department of Pediatrics, University of Iowa. The protocol was approved by the University of Iowa Committee on Research Involving Human Subjects. The parents of the infants were fully informed and consent forms were signed. The infants were managed as previously described $(3,4)$ except that formula was the sole source of energy intake until 140 days of age. As in other reports, we have used particular age designations (e.g. 112 days) although each of these ages in practice may be \pm 4 days.

Feedings. From birth to 112 days of age and from 128 to 196 days of age the infants were fed ready-to-feed (i.e. $67 \mathrm{kcal} / \mathrm{dl}$ ) milk-based formulas or formulas based on isolated soy protein. The various study designs resulted in the provision of $12 \mathrm{mg}$ of iron in the form of ferrous sulfate per liter of formula during all or most of the first 112 days of life and during the interval 128 to 196 days of age. Because we believed that absorption of the test dose of iron would be enhanced if the prior intake of iron was low (5), the infants were fed from 112 to 128 days of age a ready-to-feed milk-based formula (Enfamil, Mead Johnson and Company, Evansville, IN) providing $1.5 \mathrm{mg}$ of iron in the form of ferrous sulfate per liter of formula. Commercially prepared strained foods were introduced into the diet at 140 days of age.

Blood samples. Infants visited the Division of Nutrition at specified ages from soon after birth until completion of study. These visits included ages 84, 112, 140, 168, and 196 days. With few exceptions, a sample of $6 \mathrm{ml}$ venous blood was obtained at each of these visits.

Administration of ${ }^{58} \mathrm{Fe}$ label. A preparation of ${ }^{58} \mathrm{Fe}$-enriched elemental iron powder under inert atmosphere was purchased from Oak Ridge National Laboratory (Oak Ridge, TN). The isotopic composition of this preparation was (weight \%) ${ }^{54} \mathrm{Fe}$ $1.07,{ }^{56} \mathrm{Fe} 23.1,{ }^{57} \mathrm{Fe} 1.84,{ }^{58} \mathrm{Fe} 74.0$. The natural isotopic composition of iron (weight \%) is ${ }^{54} \mathrm{Fe} 5.61,{ }^{56} \mathrm{Fe} 91.9,{ }^{57} \mathrm{Fe} 2.18,{ }^{58} \mathrm{Fe}$ 0.322 .

The elemental iron powder was dissolved in $1 \mathrm{~N}$ sulfuric acid as previously described (2) and stored under nitrogen in sealed ampoules, each containing $1.95 \mathrm{mg}$ of total iron as ferrous sulfate, including $1.44 \mathrm{mg}$ of ${ }^{58} \mathrm{Fe}$, in $5 \mathrm{ml}$. The solution $\mathrm{pH}$ was $1.8 \pm$ 0.1 . For administration to the infant, $84 \mathrm{mg}$ of sodium ascorbate, $400 \mathrm{mg}$ of sucrose, and 1 drop of cherry flavor were added directly to the ampoule. The large dose of sodium ascorbate was added to enhance iron absorption (6) and the sucrose and cherry flavor to increase palatability. The contents were mixed gently by drawing a portion of the solution into a syringe with an 18- 
gauge needle and returning it to the ampoule. This procedure was repeated several times and the entire volume was then delivered from the syringe into the infant's mouth. Neither vial nor syringe was rinsed.

At age 126 days each infant visited the Division of Nutrition and was given the dose of $1.95 \mathrm{mg}$ of iron (containing $1.44 \mathrm{mg}$ of ${ }^{58} \mathrm{Fe}$ ) orally midmorning, approximately $2 \mathrm{~h}$ after and $2 \mathrm{~h}$ before a formula feeding. Two of the previously reported infants (subjects 3165 and 3342) were given a second dose of ${ }^{58} \mathrm{Fe}$ in the same amount and in the same manner on the next day. The first blood sample after administration of ${ }^{58} \mathrm{Fe}$ was obtained 14 days after dosing and follow-up samples were obtained 42 and 70 days after dosing.

Laboratory methods. All blood determinations were performed with venous blood or serum. Hb concentration was determined by the cyanmet-Hb method (catalog no. 368555, Boehringer Mannheim Diagnostics, Indianapolis, IN) and hematocrit with heparinized capillary tubes centrifuged at $13,000 \times g$ for $10 \mathrm{~min}$. Serum ferritin concentration was determined by radioimmunoassay (catalog no. D-4401, Micromedic Systems, Inc., Horsham, PA). Blood smears stained with brilliant cresyl blue were counted for reticulocytes with the aid of a Miller Disc (American Optical Corporation, Buffalo, NY). Four slides were counted and the values obtained therefore represent 2000 erythrocytes.

The ${ }^{58} \mathrm{Fe} /{ }^{57} \mathrm{Fe}$ isotope ratio was measured by ICP/MS as described previously (2). The ratio of the least abundant $\left({ }^{58} \mathrm{Fe}\right)$ to the next least abundant $\left({ }^{57} \mathrm{Fe}\right)$ isotope of iron provides for the greatest precision of measurement. Samples $(1.0 \mathrm{ml}$ or less) of heparinized whole blood were wet ashed with concentrated $\mathrm{HNO}_{3}$ and small amounts of $\mathrm{H}_{2} \mathrm{O}_{2}$. The digest solutions were diluted with water and the $\mathrm{pH}$ adjusted to $2.0 \pm 0.1$ by addition of $\mathrm{NH}_{4} \mathrm{OH}$. Iron was precipitated with the chelating agent, ammonium pyrrolidinedithiocarbamate and the precipitate redissolved in the least possible volume of concentrated $\mathrm{HNO}_{3}$. Solution volume was adjusted with deionized water to yield iron concentration of about $10 \mu \mathrm{g} / \mathrm{ml}$.

The ${ }^{58} \mathrm{Fe} /{ }^{57} \mathrm{Fe}$ ratio was expressed on a weight/weight basis $(\mu \mathrm{g}$ ${ }^{58} \mathrm{Fe} / \mu \mathrm{g}{ }^{57} \mathrm{Fe}$ ) and denoted as $\mathrm{MIR}_{58 / 57}$. Isotope standards for daily instrument calibration were prepared from solutions of human blood digested in the same manner as unknown samples. They were spiked with increasing amounts of enriched ${ }^{58} \mathrm{Fe}$ solution to provide isotope ratios covering the range of anticipated isotope ratios in unknown samples. The $\mathrm{MIR}_{58 / 57}$ of the isotope standards were calculated from the iron content of the blood digests determined before spiking and the known amount of ${ }^{58} \mathrm{Fe}$ and ${ }^{57} \mathrm{Fe}$ in each spike.

Unknown samples and isotope standards were analyzed for the $\mathrm{MIR}_{58 / 57}$ using the Elan $250 \mathrm{ICP} / \mathrm{MS}$ System (SCIEX, Inc., Thornhill, Ontario, Canada) operated in the isotope ratio mode. Normally, the mean of ten sequential measurements of the ion beam intensities was recorded. No background corrections were made. This value was referred to as the $\mathrm{MR}_{58 / 57}$. The coefficient of variation for the 10 measurements was usually less than $1 \%$. Isotope standards were run daily. To avoid the possibility of contamination, the standards were run after the unknown samples. The value of $\mathrm{MR}_{58 / 57}$ is not affected by changes in the ion intensity that might occur during the course of several hours of operation. For each day of operation the values of $\mathrm{MR}_{58 / 57}$ for isotope standards were plotted against the respective calculated $\mathrm{MIR}_{58 / 57}$ values. MIR $58 / 57$ values of unknown samples were read from the resulting least-squares regression equation.

Calculation of quantity of administered ${ }^{58} \mathrm{Fe}$ incorporated into erythrocytes. The quantity of administered ${ }^{58} \mathrm{Fe}$ incorporated into erythrocytes $\left({ }^{58} \mathrm{Fe}_{\mathrm{inc}}\right)$ at a specified time $\mathrm{t}$ after administration of the dose of ${ }^{58} \mathrm{Fe}$ was calculated as follows:

$$
{ }^{58} \mathrm{Fe}_{\text {inc }}=\frac{\mathrm{MIR}_{58 / 57}{ }^{{ }_{5}}-\mathrm{MIR}^{\circ}{ }_{58 / 57}}{\mathrm{MIR}^{\mathrm{o}}{ }_{58 / 57}} \times \mathrm{Fe}_{\text {circ }} \times 0.00322
$$

where ${ }^{58} \mathrm{Fe}_{\text {inc }}$ is expressed in $\mathrm{mg}, \mathrm{MIR}^{\mathrm{t}}{ }_{58 / 57}$ is the determined
$\mathrm{MIR}_{58 / 57}$ at time $\mathrm{t}$ after dosing, $\mathrm{MIR}_{58 / 57}{ }$ is the determined baseline ratio, $\mathrm{Fe}_{\text {circ }}$ is the quantity of total circulating iron $(\mathrm{mg})$ at time $t$, and 0.00322 is the natural abundance (weight fraction) of ${ }^{58} \mathrm{Fe}$.

The quantity of total circulating iron (mg) was estimated as follows:

$$
\mathrm{Fe}_{\text {circ }}=\mathrm{BV} \times \mathrm{Hb} \times 3.47
$$

where $\mathrm{BV}$ is blood volume in $\mathrm{ml}$, assumed to be $65 \mathrm{ml} / \mathrm{kg}$ of body weight, $\mathrm{Hb}$ concentration is in $\mathrm{g} / \mathrm{ml}$, and 3.47 is the concentration of iron in $\mathrm{Hb}(\mathrm{mg} / \mathrm{g})$. The assumed value for blood volume per unit of body weight is almost identical to the mean value of $66 \mathrm{ml} / \mathrm{kg}$ reported by Bratteby (7) for eight normal infants between 100 and 138 days of age.

${ }^{58} \mathrm{Fe}_{\text {inc }}$ was expressed either absolutely $(\mathrm{mg})$ or as a percentage of the administered dose of ${ }^{58} \mathrm{Fe}$ and is henceforth referred to as "circulating ${ }^{58} \mathrm{Fe}$ label."

Use of repeated $M I R_{58 / 57}$ determinations for estimate of error. When a radioactive iron tracer, ${ }^{59} \mathrm{Fe}$ or ${ }^{55} \mathrm{Fe}$, is administered orally to normal or iron-deficient adult subjects, $80 \%$ or more of the absorbed dose appears promptly (i.e. within 10 days) in the circulating erythrocytes (1). Little is known about the extent to which newly absorbed iron is incorporated into erythrocytes of infants; however, with infants, as with hematologically normal and iron-deficient adults, it seems probable that newly absorbed iron has priority for incorporation into erythrocytes. Thus, enrichment with ${ }^{58} \mathrm{Fe}$ will be found predominantly in erythrocytes formed in close temporal proximity to dosing with ${ }^{58} \mathrm{Fe}$. Erythrocytes that are eliminated from the circulation between 140 and 196 days of age will be almost exclusively older cells that are not enriched with ${ }^{58} \mathrm{Fe}$, and new erythrocytes appearing in the circulation between 140 and 196 days of age will have been formed primarily with iron absorbed during that interval. Small amounts of the ${ }^{58} \mathrm{Fe}$ label absorbed at age 126 days and not incorporated into erythrocytes by 140 days of age might be incorporated into erythrocytes between 140 and 196 days of age, but for these infants who were receiving generous intakes of iron daily, such contribution to erythrocyte ${ }^{58} \mathrm{Fe}$ will probably be trivial. Thus, the $\mathrm{MIR}_{58 / 57}$ determined at 140 days of age (i.e. 14 days after administration of iron) will be slightly more than the $\mathrm{MIR}_{58 / 57}$ determined at age 168 days, and the value at age 168 days will be slightly more than that at age 196 days. However, the quantity of circulating ${ }^{58} \mathrm{Fe}$ label should remain constant.

We therefore estimated the error of the method from the variation in the quantities of ${ }^{58} \mathrm{Fe}$ label in the circulation at ages 140,168 , and 196 days.

\section{RESULTS}

Data on body weight, $\mathrm{Hb}$ concentration, hematocrit, serum ferritin concentration, reticulocyte count, and $\mathrm{MIR}_{58 / 57}$ are presented in Table 1 for each infant at ages 84, 112, 140, 168, and 196 days.

There were no significant age-related changes in $\mathrm{Hb}$ concentration, hematocrit, or reticulocyte count. However, serum ferritin concentrations were greater at younger than at older ages. The decrease in ferritin concentration was significant for the age interval 84 to 196 days (analysis of variance: linear trend, $p<$ 0.04).

$M I R_{58 / 57}$ values and circulating ${ }^{58} \mathrm{Fe}$ label. The $\mathrm{MIR}_{58 / 57}$ at the natural abundance level is 0.1475 (i.e. $0.00322 \div 0.02183$ ). Incompletely understood factors believed to relate to instrument operation result in variation in determined $\mathrm{MIR}^{\circ}{ }_{58 / 57}$ (Table 1). The mean MIR $^{\circ}{ }_{58 / 57}$ of the first four infants studied was 0.1465 (SD 0.0019, eight determinations). $\mathrm{MIR}^{\circ}{ }_{58 / 57}$ values of the five additional infants (mean 0.1438, SD 0.0020 , six determinations) were significantly $(p<0.05)$ lower. One value (subject 3378 , age 112 days) was excluded as an outlier (Table 1). In our calculations we have used the mean determined values as the baselines for the original four and the additional five infants, respectively. 
Table 1. Subject characteristics and results of laboratory determinations

\begin{tabular}{|c|c|c|c|c|c|c|c|c|c|}
\hline \multirow[b]{2}{*}{ Subject no. } & \multicolumn{9}{|c|}{ Subject } \\
\hline & $3165^{*}$ & $3342^{*}$ & $3166^{*}$ & $3343^{*}$ & 3378 & 3379 & 3382 & 3384 & 3391 \\
\hline Sex & $\mathrm{F}$ & M & $\mathrm{F}$ & $\mathrm{M}$ & $\mathrm{F}$ & $\mathrm{F}$ & $\mathrm{F}$ & $\mathrm{F}$ & M \\
\hline \multicolumn{10}{|l|}{ Age 84 days } \\
\hline Wt (g) & 5375 & 6005 & 5420 & 6105 & 4775 & 5340 & 5625 & 4865 & 4860 \\
\hline $\mathrm{Hb}(\mathrm{g} / \mathrm{dl})$ & 10.3 & 10.0 & 9.9 & 10.3 & 11.6 & 12.3 & 9.9 & & \\
\hline Hematocrit (\%) & 34.0 & 35.8 & 27.0 & 34.1 & 33.7 & 32.7 & 32.8 & & \\
\hline Reticulocyte count (\%) & & & 1.8 & & 0.3 & & 0.3 & 0.4 & \\
\hline Ferritin $(\mathrm{ng} / \mathrm{ml})$ & & 108 & 66 & 48 & 190 & & 170 & 152 & \\
\hline MIR 58/57 & 0.1496 & 0.1448 & 0.1473 & 0.1440 & 0.1418 & & 0.1458 & 0.1432 & \\
\hline \multicolumn{10}{|l|}{ Age 112 days } \\
\hline Wt (g) & 6140 & 6805 & 6000 & 6820 & 5130 & 5780 & 6415 & 5355 & 5735 \\
\hline $\mathrm{Hb}(\mathrm{g} / \mathrm{dl})$ & 11.3 & 10.9 & 9.4 & 11.0 & 11.5 & 12.1 & 10.6 & 11.5 & 10.2 \\
\hline Hematocrit $(\%)$ & 35.2 & 36.1 & 30.2 & 33.2 & 33.0 & 33.6 & 33.7 & 36.1 & 33.0 \\
\hline Reticulocyte count (\%) & & 0.3 & 0.8 & 0.2 & 0.3 & 0.2 & 0.2 & 0.4 & 0.3 \\
\hline Ferritin $(\mathrm{ng} / \mathrm{ml})$ & 51 & 21 & 35 & 40 & & 230 & 58 & 46 & 26 \\
\hline MIR 58/57 & 0.1481 & 0.1449 & 0.1475 & 0.1455 & $0.1527 \dagger$ & & 0.1468 & 0.1434 & 0.1420 \\
\hline \multicolumn{10}{|l|}{ Age 140 days } \\
\hline Wt $(\mathrm{g})$ & 6745 & 7490 & 6535 & 7685 & 5500 & 6500 & 7000 & 6075 & 6525 \\
\hline $\mathrm{Hb}(\mathrm{g} / \mathrm{dl})$ & 11.4 & 11.4 & 10.8 & 10.9 & 11.6 & 11.6 & 11.3 & 11.9 & 10.8 \\
\hline Hematocrit (\%) & 36.0 & 35.2 & 33.5 & 33.5 & 33.9 & 36.5 & 35.2 & 37.4 & 33.2 \\
\hline Reticulocyte count (\%) & 0.3 & 0.3 & 1.1 & 0.3 & 0.1 & 0.3 & 0.3 & 0.3 & 0.3 \\
\hline Ferritin $(\mathrm{ng} / \mathrm{ml})$ & 22 & 15 & 28 & 27 & 96 & & 42 & 33 & 33 \\
\hline MIR 58/57 & 0.2630 & 0.2607 & 0.1898 & 0.1686 & 0.1547 & 0.1566 & 0.1573 & 0.1811 & 0.2062 \\
\hline \multicolumn{10}{|l|}{ Age 168 days } \\
\hline Wt (g) & 7200 & 7885 & 6800 & 8175 & 58975 & 6820 & 7480 & 6600 & 6975 \\
\hline $\mathrm{Hb}(\mathrm{g} / \mathrm{dl})$ & 11.3 & 11.2 & 10.3 & 11.2 & 11.9 & 11.2 & 10.1 & 12.0 & 10.6 \\
\hline Hematocrit (\%) & 36.8 & 36.1 & 33.0 & 36.3 & 35.5 & 35.3 & 32.4 & 37.8 & 33.6 \\
\hline Reticulocyte count (\%) & 0.1 & 0.3 & 0.5 & 0.3 & 0.4 & & 0.4 & 0.3 & 0.3 \\
\hline Ferritin $(\mathrm{ng} / \mathrm{ml})$ & 27 & 16 & 38 & 11 & & 150 & 37 & 26 & 26 \\
\hline MIR 58/57 & 0.2649 & 0.2521 & 0.1893 & 0.1686 & 0.1607 & 0.1533 & 0.1574 & 0.1793 & 0.2014 \\
\hline \multicolumn{10}{|l|}{ Age 196 days } \\
\hline Wt $(g)$ & 7735 & 8150 & 7395 & 8515 & 6410 & 7405 & 7810 & 7135 & 7630 \\
\hline $\mathrm{Hb}(\mathrm{g} / \mathrm{dl})$ & 11.5 & 11.5 & 10.4 & 11.1 & 11.3 & 11.0 & 11.2 & 11.2 & 10.1 \\
\hline Hematocrit (\%) & 38.4 & 35.2 & 33.9 & 34.8 & 34.9 & 34.1 & 32.5 & 36.4 & 32.0 \\
\hline Reticulocyte count (\%) & 0.4 & 0.5 & 0.8 & 0.3 & & 0.3 & 0.4 & 0.3 & 0.3 \\
\hline Ferritin (ng/ml) & 28 & 26 & 48 & 24 & 44 & 120 & 18 & 48 & 45 \\
\hline MIR 58/57 & 0.2486 & 0.2408 & 0.1856 & 0.1736 & 0.1619 & 0.1563 & 0.1570 & 0.1778 & 0.1963 \\
\hline
\end{tabular}

* Subjects reported previously (2).

$\uparrow$ Value excluded.

Values for circulating ${ }^{58} \mathrm{Fe}$ label $\left({ }^{58} \mathrm{Fe}_{\text {inc }}\right)$ are presented in Table 2. The difference between values for 140,168, and 196 days of age was not statistically significant (analysis of variance). For each subject the mean of all three values is presented both in absolute terms $(\mathrm{mg})$ and as a percentage of the administered dose. The circulating ${ }^{58} \mathrm{Fe}$ label accounted for 3.2 to $16.0 \%$ of the administered dose, with a geometric mean of $7.9 \%$. The data in Table 2 include results for four subjects identified in our earlier report (2). The values for percentage of circulating ${ }^{58} \mathrm{Fe}$ label presented in Table 2 differ somewhat from those presented previously because of erroneous values for $\mathrm{Hb}$ concentrations in the earlier report.

Relation between circulating ${ }^{58} \mathrm{Fe}$ label and indices of iron nutritional status. Because we did not obtain a sample of blood on the day on which the dose of ${ }^{58} \mathrm{Fe}$ was administered (age 126 days), we used the average value for 112 and 140 days of age as most representative for $\mathrm{Hb}$ concentration, hematocrit, reticulocyte count, and serum ferritin concentration to explore the relation between percentage circulating label and each of the specified hematologic indices:

The percentage circulating ${ }^{58} \mathrm{Fe}$ label was not significantly correlated with $\mathrm{Hb}$ concentration, hematocrit, or reticulocyte count but was correlated with serum concentration of ferritin (Spearman rank correlation, $r=-0.867, p<0.01$; log-log correlation $r=-0.836, p<0.01$ ). As may be seen from Figure 1 , at low levels of serum ferritin ( $40 \mathrm{ng} / \mathrm{ml}$ or less), a relatively high percentage of the label was present in circulating erythrocytes ( 6 infants, range 7.4 to $16.0 \%$ of dose). However, at higher levels of serum ferritin, a smaller percentage of the label appeared in the circulation (three infants, range 3.2 to $3.8 \%$ of dose). On the whole, serum ferritin concentration explained 70 to $75 \%$ of the variation in circulating ${ }^{58} \mathrm{Fe}$ label ( $r^{2}$ values).

Estimation of error. As an initial approach to estimating the error of the method, we determined the uncertainty of the value of ${ }^{58} \mathrm{Fe}_{\text {inc }}$ (equation 1) resulting solely from the uncertainties in the measurement of $\mathrm{MIR}_{58 / 57}{ }$ and $\mathrm{MIR}_{58 / 57}$. For consideration, we chose a $7000 \mathrm{~g}$ infant with $\mathrm{Hb}$ concentration of $0.11 \mathrm{~g} / \mathrm{ml}$ and $\mathrm{MIR}^{\circ}{ }_{58 / 57}$ of 0.1456 (SD 0.0015). With the assumption that the coefficient of variation of $\mathrm{MIR}_{58 / 57}$ determinations was $1 \%$ as previously reported (2), we calculated the uncertainty of ${ }^{58} \mathrm{Fe}_{\text {inc }}$ by propagation of errors through equation 1 with 1) $\mathrm{MIR}^{\mathrm{t}}{ }_{58 / 57}$ of 0.1602 and 2) $\mathrm{MIR}_{58 / 57}^{\mathrm{t}}$ of 0.2184 . In example 1), the calculated value for ${ }^{58} \mathrm{Fe}_{\text {inc }}$ is $3.9 \%$ of intake (SD $0.6 \%$; CV $15 \%$ ). In example 2 ), the calculated value for ${ }^{58} \mathrm{Fe}_{\text {inc }}$ is $19.4 \%$ (SD $0.7 \%$; CV $3.6 \%$ ).

A separate approach to estimating the error was provided by the variation with each subject between values for circulating ${ }^{58} \mathrm{Fe}$ label at ages 140, 168, and 196 days (Table 2). Although the $\mathrm{SD}$ of percentage circulating label were relatively low, ranging from 0.22 to $1.28 \%$ (arithmetic mean $0.62 \%$ ) of the dose, the $\mathrm{CV}$ ranged from 1.0 to $30.5 \%$ (arithmetic mean $9.7 \%$ ), the highest value pertaining, not unexpectedly, to one of the subjects with relatively low percentage circulating ${ }^{58} \mathrm{Fe}$ label. For the six 
Table 2. Circulating ${ }^{58} \mathrm{Fe}$ label

\begin{tabular}{|c|c|c|c|c|c|c|c|c|}
\hline \multirow[b]{2}{*}{ Subject } & \multicolumn{5}{|c|}{ Circulating ${ }^{58} \mathrm{Fe}$ label (mg) } & \multicolumn{3}{|c|}{$\begin{array}{c}\text { Circulating }{ }^{58} \mathrm{Fe} \text { label (\% of } \\
\text { dose) }\end{array}$} \\
\hline & 140 days & 168 days & 196 days & Mean & SD & Mean & $\mathrm{SD}$ & $\mathrm{CV}$ \\
\hline 3165 & 0.4441 & 0.4776 & 0.4502 & 0.4573 & 0.0178 & 15.9 & 0.62 & 3.9 \\
\hline 3342 & 0.4834 & 0.4623 & 0.4382 & 0.4613 & 0.0226 & 16.0 & 0.79 & 4.9 \\
\hline 3166 & 0.1515 & 0.1486 & 0.1491 & 0.1497 & 0.0016 & 10.4 & 0.11 & 1.0 \\
\hline 3343 & 0.0918 & 0.1003 & 0.1270 & 0.1064 & 0.0184 & 7.4 & 1.28 & 17.3 \\
\hline 3378 & 0.0351 & 0.0597 & 0.0662 & 0.0537 & 0.0164 & 3.7 & 1.14 & 30.5 \\
\hline 3379 & 0.0487 & 0.0366 & 0.0514 & 0.0456 & 0.0079 & 3.2 & 0.55 & 17.3 \\
\hline 3382 & 0.0539 & 0.0519 & 0.0583 & 0.0547 & 0.0033 & 3.8 & 0.23 & 6.0 \\
\hline 3384 & 0.1362 & 0.1420 & 0.1372 & 0.1385 & 0.0031 & 9.6 & 0.22 & 2.2 \\
\hline 3391 & 0.2221 & 0.2151 & 0.2043 & 0.2138 & 0.0089 & 14.8 & 0.62 & 4.2 \\
\hline Mean & 0.1852 & 0.1882 & 0.1869 & 0.1868 & 0.0111 & $7.9^{*}$ & & \\
\hline
\end{tabular}

* Geometric mean (arithmetic mean 9.4).

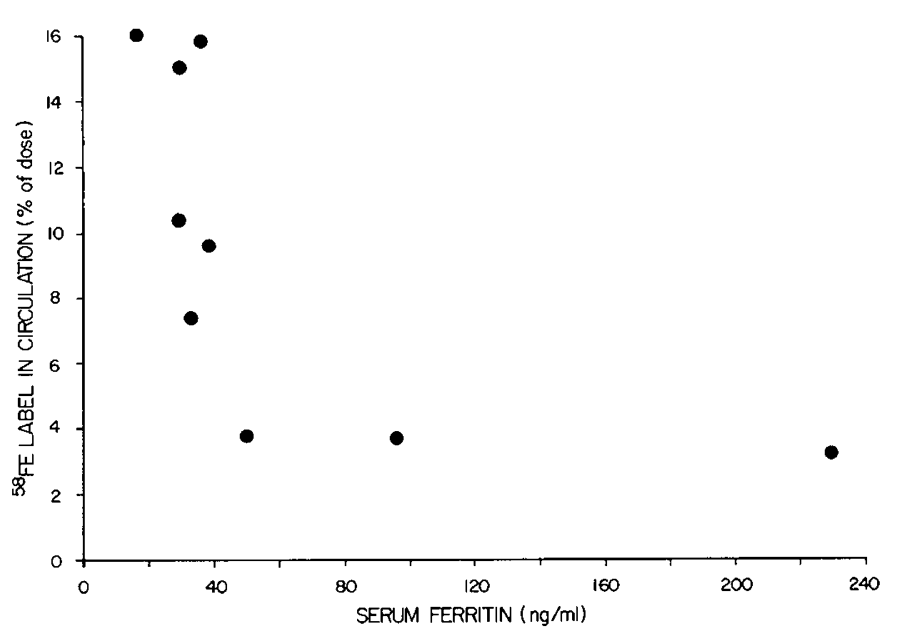

Fig. $1 .{ }^{58} \mathrm{Fe}$ label (\% of dose) in circulation (mean value for 140,168 , and 196 days) in relation to serum concentration of ferritin (mean value for 112 and 140 days).

subjects with ferritin concentration of less than $40 \mathrm{ng} / \mathrm{ml}$ the mean coefficient of variation was $5.6 \%$.

The similarity of the SD and the CV obtained by the propagation of errors approach (which reflects only the error in $\mathrm{MIR}_{58 /}$ 57 determinations) and those calculated from the determined values for ${ }^{58} \mathrm{Fe}_{\text {inc }}$ at ages 140,168 , and 196 days suggests that the major source of error is in the MIR $_{58 / 57}$ determinations.

\section{DISCUSSION}

With the exception of our preliminary report concerning determination of ${ }^{58} \mathrm{Fe}$ enrichment of erythrocytes by ICP/MS (2), studies of iron availability with stable isotopes have been based on determinations of fecal excretion of the isotope $(8,9)$. Data presented herein suggest the feasibility of studies in which ${ }^{58} \mathrm{Fe}$ enrichment of erythrocytes rather than fecal excretion of ${ }^{58} \mathrm{Fe}$ serves as the endpoint. Several questions, such as the relative absorption of fortification iron from foods, can be answered less expensively and probably more convincingly by determining ${ }^{58} \mathrm{Fe}$ enrichment of erythrocytes than by ${ }^{58} \mathrm{Fe}$ metabolic balance studies.

There is only one previous report of erythrocyte incorporation of an iron isotope by infants after an oral dose of iron administered between feedings. Rios et al. (10) fed $1.44 \mathrm{mg}$ of ferrous ascorbate tagged with ${ }^{59} \mathrm{Fe}$ under conditions quite similar to those of our study. In three feeding groups of 13 to 15 infants each, geometric mean retentions were reported to be $6.4,7.8$, and $5.8 \%$ of intake. If we assume, as was done by Rios et al.
(10), that $90 \%$ of absorbed iron was present in erythrocytes 14 days after administration of the test dose, geometric mean retention in our study was $8.8 \%$ of intake $(7.9 \% \div 0.9)$.

Little information is available concerning the percentage of absorbed iron promptly incorporated into the circulating erythrocytes of infants. Garby et al. (11) administered small amounts of ${ }^{59} \mathrm{Fe}$ intravenously to infants and determined the percentage of the administered dose present in circulating erythrocytes at various intervals thereafter. Judging from the graphic data presented by these authors, 9 to 14 days after administration approximately $65 \%$ of the dose was present in erythrocytes of one infant injected at age 65 days, and approximately $85 \%$ of the dose was present in erythrocytes of three infants injected at ages 81 to 129 days. Data are not available concerning older infants and we find no reason to reject the assumption of Rios et al. (10) that $90 \%$ of retained iron appeared promptly in erythrocytes of the 4- to 6-month-old infants in their study. To obtain additional information on this point, we are conducting ${ }^{58} \mathrm{Fe}$ metabolic balance studies concurrently with studies of ${ }^{58} \mathrm{Fe}$ incorporation into erythrocytes.

Although the report by Rios et al. (10) is the only report of erythrocyte incorporation of radioiron given to infants between feedings, retention of oral doses of radioiron given to infants between feedings has been determined by metbolic balance studies $(12,13)$ or by whole body counting (14-16). In all but two of these studies $(14,15)$, the dose of iron was much higher [30 to $60 \mathrm{mg}$ in the study of Schulz and Smith (12)] or lower [20 $\mu \mathrm{g}$ or less in the studies by Garby and Sjölin (13), and by Saarinen et al. (16)]. Therefore, the most relevant data appear to be those of Heinrich et al. $(14,15)$.

Heinrich et al. $(14,15)$ studied retention of iron by infants with normal iron stores given a dose of iron $(0.56,5$, or $10 \mathrm{mg})$ between feedings $(5 \mathrm{~h}$ after a feeding and $2 \mathrm{~h}$ before the next feeding) with $17.5 \mathrm{mg}$ ascorbic acid. Mean retention was $20.7 \%$ (S.D. 8.0) with a dose of $0.56 \mathrm{mg}$ (14), $18 \%$ (S.D. 5\%) with a dose of $5 \mathrm{mg}(15)$, and $7.6 \%$ (S.D. $1.2 \%$ ) with a dose of $10 \mathrm{mg}$ (15).

If we assume that $90 \%$ of the retained iron is present in the circulating erythrocytes 14 days after administering the test dose, the extent of retention in our study with the dose of $1.95 \mathrm{mg}$ of iron was substantially less than that reported by Heinrich et al. $(14,15)$. In our study, the greatest retention was probably no more than $17.7 \%$ of the dose (Table 2, subject $3342: 16.0 \% \div$ $0.9=17.7 \%$ ), a value slightly less than the mean values reported by Heinrich et al. $(14,15)$ with doses of $0.56 \mathrm{mg}(20.7 \%$ retention) or $5 \mathrm{mg}$ ( $18.0 \%$ retention).

The most likely explanation for the difference in retention reported by Heinrich et al. $(14,15)$ and by us is the timing of ${ }^{58} \mathrm{Fe}$ administration in relation to feeding. The infants studied by Heinrich et al. $(14,15)$ were given the dose of iron $5 \mathrm{~h}$ after a feeding, whereas the infants in our study were given the dose 2 
$\mathrm{h}$ after a feeding. Thus, in our study there was greater likelihood of inhibition of iron absorption by mixing of the dose with formula or formula components in the stomach or upper small intestine.

Studies of adult subjects given oral doses of radioisotopes of iron under standardized, fasting conditions have demonstrated a significant inverse relationship between percentage of the dose of ${ }^{59} \mathrm{Fe}$ absorbed and serum ferritin concentration $(17-22)$. As would be expected, the correlation is higher when the population studied includes both normal and iron-deficient subjects. Even when the analysis is restricted to iron-sufficient subjects, the correlation is significant. In iron-sufficient adult subjects, Walters et al. (18) reported a correlation coefficient of $-0.398(p<0.005)$ for the regression of percent absorption on serum ferritin concentration and Heinrich et al. (20) reported a correlation coefficient of $-0.356(p<0.01)$ for the regression of log serum ferritin concentration on percent absorption. Neither Walters et al. (18) nor Heinrich et al. (20) calculated the regression on a sex-specific basis, although there was a significant sex-related difference in serum concentration of ferritin among the subjects studied by Walters et al. (18) and probably among the subjects studied by Heinrich et al. (20).

Because the infants in our study were a relatively homogeneous group with respect to birth weight and known intake of iron from the time of birth, and because our conditions of administration of the iron dose were less well controlled (i.e. the dose could not be given in the postabsorptive state), we were surprised to observe the relatively high correlation between percent of circulating ${ }^{58} \mathrm{Fe}$ label and serum ferritin concentration.

The availability of normal, term infants for longitudinal study made it possible for us to adhere to a rather rigid protocol. The dose of ${ }^{58} \mathrm{Fe}$ was administered to all infants under standardized conditions at the same age (126 \pm 4 days) and follow-up samples of blood were obtained at 140, 168, and 196 days of age. Calculations based on these three follow-up values permitted an estimate of error of the value obtained in the determination of erythrocyte incorporation of ${ }^{58} \mathrm{Fe}$. This error, which includes the errors in the determinations of $\mathrm{MIR}_{58 / 57}$ and $\mathrm{Hb}$ concentration and the effect of certain assumptions, was rather modest (generally less than $1 \%$ of the dose) (Table 2). Such errors are probably acceptable for within-subject comparisons of iron availability from foods. In view of the large between-subject variation (3.2 to $16.0 \%$ of the dose incorporated into erythrocytes), we are pessimistic about the usefulness of study designs based on group comparisons of infants in this age group. However, group comparisons of older infants with less diversity in iron nutritional status (as reflected by serum ferritin concentration) may be feasible.

The analytical method of ICP/MS used herein is potentially capable of an order of magnitude better precision $(0.1 \%)$ than achieved at present on a routine basis (2). If such an analytical precision could be achieved routinely, a number of important advances would be possible. The most significant of these concern the simultaneous use of two stable isotopes of iron- $-{ }^{58} \mathrm{Fe}$ and ${ }^{57} \mathrm{Fe}$. The ability to make precise measurements of two stable isotopes of iron would greatly increase the value of the approach. Absorption of nonheme iron from a meal, determined with the use of one stable isotope as an extrinsic tag, could be related to absorption of iron (tagged with the second stable isotope) from an aqueous solution of iron administered under standard conditions. Alternatively, iron absorption from two foods or two meals could be compared, one food or meal fed on the first day and the other on the second day. Finally, one stable isotope could be used to tag nonheme iron and the other to tag heme iron in the same meal.

\section{REFERENCES}

1. Bothwell TH, Charlton RW, Cook JD, Finch CA 1979 Iron Metabolism in Man. Blackwell Scientific Publications, Oxford

2. Janghorbani M, Ting BTG, Fomon SJ 1986 Erythrocyte incorporation of ingested stable isotope of iron $\left({ }^{58} \mathrm{Fe}\right)$. Am J Hematol 21:277-288

3. Fomon SJ, Thomas LN, Filer LJ Jr, Ziegler EE, Leonard MT 1971 Food consumption and growth of normal infants fed milk-based formulas. Acta Paediatr Scand [Suppl] 223:

4. Ziegler EE, Fomon SJ 1982 Methods in infant nutrition research: balance and growth studies. Acta Paediatr Scand [Suppl] 299:90-96

5. Turnbull A 1974 Iron absorption. In: Jacobs A, Worwood M (eds) Iron in Biochemistry and Medicine. Academic Press, New York, pp 369-403

6. Hallberg L 1981 Bioavailability of dietary iron in man. Ann Rev Nutr 1:123147

7. Bratteby L-E 1968 Studies on erythro-kinetics in infancy. XI. The change in circulating red cell volume during the first five months of life. Acta Paediat Scand 57:215-224

8. Janghorbani M, Ting BTG, Young VR 1980 Absorption of iron in young men studied by monitoring excretion of a stable iron isotope $\left({ }^{58} \mathrm{Fe}\right)$ in feces. $\mathrm{J}$ Nutr 1 10:2190-2197

9. Fairweather-Tait SJ, Minski MJ 1986 Studies on iron availability in man, using stable isotope techniques. Br J Nutr 55:279-285

10. Rios E, Hunter RE, Cook JD, Smith NJ, Finch CA 1975 The absorption of iron as supplements in infant cereal and infant formulas. Pediatrics 55:686693

11. Garby L, Sjölin S, Vuille J-C 1963 Studies on erythro-kinetics in infancy. III. Disappearance from plasma and red-cell uptake of radio-active iron injected intravenously. Acta Paediatr 52:537-553

12. Schulz J, Smith NJ 1958 A quantitative study of the absorption of food iron in infants and children. Am J Dis Child 95:109-119

13. Garby L, Sjölin S 1959 Absorption of labelled iron in infants less than three months old. Acta Paediatr Scand [Suppl] 48 (117):24-28

14. Heinrich HC, Bartels H, Goetze Ch, Schäfer KH 1969 Normalbereich der intestinalen Eisenresorption bei Neugeborenen und Säuglingen. Klin Wochenschr 47:984-991

15. Heinrich HC, Gabbe EE, Whang DH, Bender-Gotze Ch, Schäfer KH 1975 Ferrous and hemoglobin- ${ }^{59} \mathrm{Fe}$ absorption from supplemented cow milk in infants with normal and depleted iron stores. Z Kinderheilk 120:251-258

16. Saarinen UM, Siimes MA, Dallman PR 1977 Iron absorption in infants: High bioavailability of breast milk iron as indicated by the extrinsic tag method of iron absorption and by the concentration of serum ferritin. J Pediatr
$91: 36-39$

17. Cook JD, Lipschitz DA, Miles LEM, Finch CA 1974 Serum ferritin as a measure of iron stores in normal subjects. Am $\mathbf{J}$ Clin Nutr 27:681-687

18. Walters GO, Jacobs A, Worwood M, Trevett D, Thomson W 1975 Iron absorption in normal subjects and patients with idiopathic haemochromatosis: relationship with serum ferritin concentration. Gut 16:188-192

19. Disler PB, Lynch SR, Charlton RW, Torrance JD, Bothwell TH, Walker RB Mayet F 1975 The effect of tea on iron absorption. Gut 16:193-200

20. Heinrich HC, Brüggemann J, Gabbe EE, Gläser M 1977 Correlation between diagnostic ${ }^{59} \mathrm{Fe}^{2+}$-absorption and serum ferritin concentration in man. $Z$ Naturforsch 32c:1023-1025

21. Charlton RW, Derman D, Skikne B, Lynch SR, Sayers MH, Torrance JD, Bothwell TH 1977 Iron stores, serum ferritin and iron absorption. In: Brown EB, Aisen P, Fielding J, Crichton RR (eds) Proteins of Iron Metabolism. Grune and Stratton, New York, pp 387-392

22. Bezwoda WR, Bothwell TH, Torrance JD, MacPhail AP, Charlton RW, Kay G, Levin J 1979 The relationship between marrow iron stores, plasma ferritin concentrations and iron absorption. Scand J Haematol 22:113-120 